\title{
Retrospectiva constructiva e histórica del Panóptico de lbagué, Colombia
}

\author{
Mario Fernando Cifuentes Segovia
}

\section{Retrospectiva histórica}

Antes de dar inicio a la descripción constructiva del edificio Panóptico de lbagué es importante resaltar la retrospectiva de esta ciudad que alberga una de las más emblemáticas e importantes construcciones no solo por su valioso lenguaje arquitectónico sino como conjunto en aspectos de tipo urbano, social, cultural e histórico.

Una vez explorados algunos aspectos históricos de la ciudad de lbagué y el departamento del Tolima, se conocerán los relacionados con la construcción del edificio para, finalmente, adentrarse en los procesos constructivos y de restauración llevados a cabo entre 2006 y 2008, fundamentales para reconocer el gran potencial constructivo que poseen la edificación patrimonial y sus alrededores.

\section{Retrospectiva histórica de la ciudad de Ibagué}

Hacia 1550 consta en acta la promisoria misión del hombre español que fundó y colonizó las tierras del Valle de las Lanzas, donde se asienta la ciudad de lbagué; "La información o probanza de los méritos del Capitán Andrés López de Galarza [...] consta que apaciguó y pobló la provincia del Valle de las Lanzas y fundó la ciudad de lbagué” (Cuartas, 1994, noviembre, p. 23).

Esta ciudad fue fundada en honor al gran cacique territorial llamado lbagué; “[...] la época de gesta de lbagué y de la heroica jornada que fue la conquista de Panches y Pijaos, la llamada pacificación de éstos y la colonización de sus tierras” (Cuartas, 1994, noviembre, p. 16). Antes de la llegada de los españoles, este territorio era habitado por los Panches y Pijaos que ocupaban el Alto Magdalena y los territorios entre los nevados del Huila, el Tolima y Quindío. El 23 de julio de 1550 el capitán español Andrés López de Galarza atravesó el río grande de la Magdalena para entrar a los territorios del actual departamento del Tolima, nombre en lengua panche que significa nieve o tierra de hielo o tierra de la montaña de hielo (Banco de la República, 2006). Allí se presentaron las condiciones adecuadas para fundar, en octubre del mismo año, la villa de San Bonifacio de lbagué del Valle de las Lanzas en el lugar que actualmente ocupa el municipio de Cajamarca. A causa de los continuos ataques de los Pijaos que reclamaban su tierra, la ciudad debió trasladarse a las cercanías del río Combeima, donde actualmente queda: "La combinación de dos factores altamente destructivos, el terremoto de 1826 y los incendios

* Cómo citar este artículo: Cifuentes, M. F. (2015). Retrospectiva constructiva e histórica del Panóptico de Ibagué, Colombia. Apuntes, 28(2), 16-29. http://dx.doi.org/10.11144/Javeriana.apc28-2.rchp 


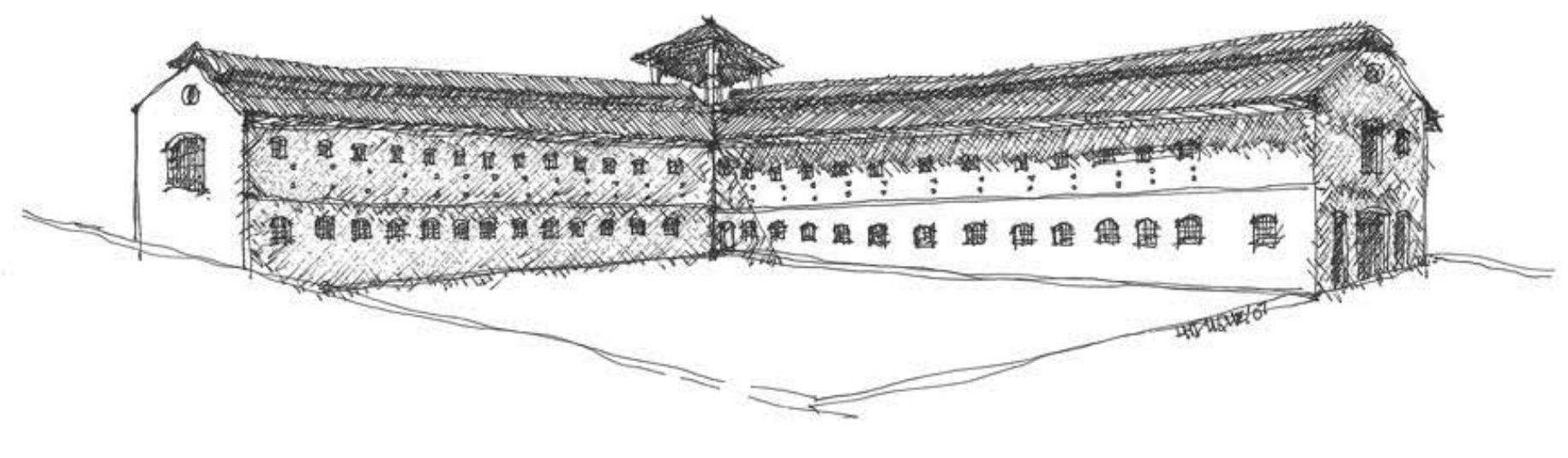

Panóptico de lbagué.

Dibujo: L. H. Duque, 2007

Fuente:

Mario Cifuentes 


\title{
Retrospectiva constructiva e histórica del Panóptico de lbagué, Colombia
}

\section{Constructive and historical retrospective of the Panopticon of lbague, Colombia}

Retrospectiva construtiva e histórica do Panopticon de lbague, Colômbia

\begin{abstract}
Mario Fernando Cifuentes Segovia
mfcifuentess@ut.edu.co

Profesor de la Facultad de Tecnologías, Programa de Arquitectura, Universidad del Tolima. Arquitecto de la Universidad Piloto de Colombia. Especialista en Restauración y Conservación del Patrimonio Arquitectónico de la Universidad La Gran Colombia. Adelanta estudios de maestría en Conservación del Patrimonio Cultural Inmueble en la Universidad Nacional de Colombia. Ponente internacional de Coibrecopa en La Plata, Argentina, septiembre de 2011.

Resumen

La ciudad de Ibagué, antiguamente llamada "Villa de San Bonifacio de Ibagué del Valle de las Lanzas", fue fundada en 1550 por el adelantado conquistador español Don Andrés López de Galarza, quien erige una población en medio de una boscosa región infestada de nativos Pijaos que la atacaron varias veces, razón por la cual pierde el concepto colonial y solo hasta 1800 retoma el carácter de población. Fue declarada ciudad republicana por excelencia hacia 1850. A finales de esta década aparece el impresionante edificio Panóptico de lbagué, reconocida construcción de planta en cruz griega, concebida en estilo neorrománico, de estructura muraria en cal y canto y complejas piezas de cerchas rey en su cubierta. Esta edificación creada por William Blackwel bajo la administración de Manuel Casabianca, estuvo destinada a albergar reclusos e internos desde 1892, uso que se extendió hasta 2003. Su intervención y restauración se inició en 2006 y hoy aún está sin finalizar. Por su carácter monumental y lenguaje propio es una de las edificaciones patrimoniales más importantes no solo de los ámbitos municipal y regional sino también en los niveles nacional y continental.
\end{abstract}

Palabras clave: arquitectura; panóptico de Ibagué; patrimonio; estructura muraria; pintura carcelaria; sobreestructura; estructura, subestructura

Abstract

The city of Ibague, formerly called "Villa de San Bonifacio de Ibagué Valley of Spears" was founded in 1550 by the leading Spanish conquistador Don Andres Lopez de Galarza, who erects a population amid a forested region infested with native Pijaos that attacked several times, why you lose the colonial concept and only until 1800 retakes the character of population. It was declared republican city par excellence to 1850. At the end of this decade the impressive Panopticon building Ibagué, known building Greek cross plan, conceived in neo-Romanesque style, wall structure in masonry and complex pieces of roof trusses king it appears on your cover. This building created by William Blackwell under the administration of Manuel Casabianca, was intended to house prisoners and internees since 1892, use that extends until 2003. His intervention and restoration began in 2006 and today is still unfinished. For its monumental character and own language it is one of the most important heritage buildings not only of the municipal and regional level but also at national and continental levels.

Keywords: architecture; panopticon of Ibague; heritage structure muraria; painting prison; superstructure; structure; substructure

Resumo

A cidade de lbagué, anteriormente chamado de "Villa de San Bonifacio de lbagué Valley of Spears" foi fundada em 1550 pelo líder conquistador espanhol Don Andres Lopez de Galarza, que erige uma população em meio a uma região de floresta infestada de Pijaos nativa que atacou várias vezes, porque você perder o conceito colonial e só até 1800, retoma o caráter da população. Foi declarado republicano excelência cidade par a 1850. No final desta década o impressionante edifício Panopticon Ibagué, conhecido construção de planta em cruz grega, concebida em

Artículo de investigación

Recepción: 4 de mayo de 2015

Aceptación: 4 de octubre de 2015

Disponible en línea: 31 de enero de 2016 estilo neo-românico, estrutura da parede em alvenaria e partes complexas de Fardos do telhado rei aparece em seu cobrir. Este edifício criado por William Blackwell sob a administração de Manuel Casabianca, foi destinado a abrigar os presos e internados desde 1892, o uso que se estende até 2003. Sua intervenção e restauração começou em 2006 e hoje ainda não está finalizado. Para o seu carácter monumental e linguagem própria que é um dos mais importantes edifícios do património, não só do nível municipal e regional, mas também a nível nacional e continental.

Palavras-chave: Arquitetura; Panopticon de Ibague; Heritage Estrutura muraria; a prisão pintura; superestrutura; estrutura; subestrutura 


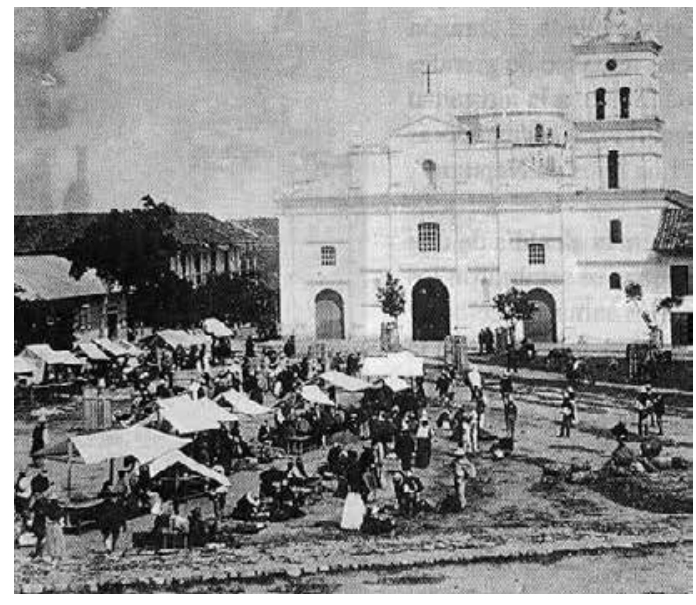

constantes de 1606 y 1851 a causa de los Pijaos, hicieron desaparecer de lbagué todo rastro [...]" (Cuartas, 1994, noviembre, p. 48).

Cabe resaltar que en la fundación inicial la ciudad se ubica en medio de los valles conformados por amplias y verdosas montañas, donde florecen ceibas, cauchos centenarios y mangos sembrados en sitios estratégicos de la ciudad, que en su configuración abrazan en sentido de protección a la ciudad y esta a su vez se extiende a manera de cono por todo el valle, una formación geográfica lograda por la presencia del cañón del río Combeima o Cutucumay en lengua pijao'. No es mucho lo que se conserva del proceso poblacional de la ciudad en épocas de la colonia debido a que los terroríficos ataques de los Pijaos produjeron su traslado de las tierras de Cajamarca al Valle de las Lanzas.

Como las grandes ciudades de España, lbagué contó desde los inicios con una plaza central en donde realizar espectáculos y reuniones de interés común -posteriormente fue llamada Plaza de Bolivar-, alrededor de la cual se establecieron las primeras casas, además de una iglesia, una sede del gobierno y un mercado central. Las construcciones, incluida la iglesia, eran de bahareque y paja, fueron acompañadas con conjuntos arquitectónicos grandiosos como el convento e iglesia de la Orden de Predicadores o Padres Dominicos (Figura 3) y un número mayor de tres ermitas en la periferia de la ciudad, entre ellas la de Santa Lucía, El Humilladero y La Soledad, importantes construcciones ya desaparecidas. Esta es la primera gran pérdida patrimonial que sufre la ciudad, lo que significó un impacto importante en el proceso urbanístico de la población: "Había sucumbido el patrimonio arquitectónico del lbagué colonial [ ] (Cuartas, 1994, noviembre, p. 50).

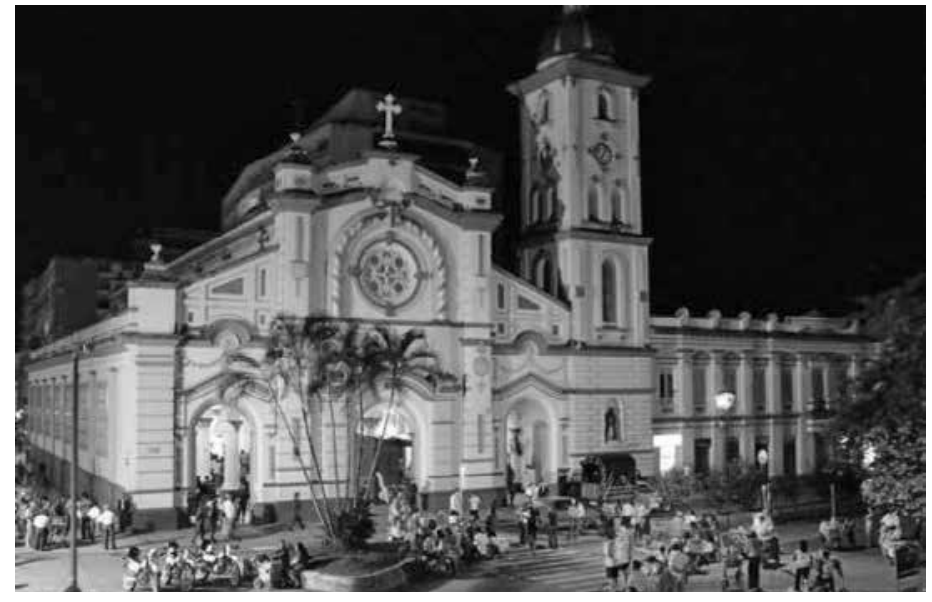

La población, tristemente, no tuvo la oportuna intervención para reconstruir su fisonomía original, entre otras razones, y principalmente, por la carencia de recursos y materiales y la falta de voluntad de los gobernantes, que en ese momento no permitieron erigir construcciones perennes debido a su carácter de ciudad de paso por el que se destacó durante un largo periodo.

Sin identidad y sin huellas visibles de su arquitectura colonial, la ciudad actual se levanta a partir de conceptos y estilos republicanos que acompañaron su florecimiento y auge. A falta de construcciones de tipo monumental, la ciudad, que seguía siendo de paso, enfrenta la tarea de destacar sus edificaciones como insignes de la región y ser reconocida como ciudad republicana por excelencia. Se inician grandes construcciones, a la Plaza de Bolívar -también conocida hoy como Parque Bolívar-, la rodean edificaciones en estilo republicano de gran importancia administrativa que aún ostentan: la casa Urrutia, la antigua Casa de Arcos, el Palacio Episcopal, la lglesia Catedral -antes llamada San Bonifacio Mártir y hoy con la advocación de la lnmaculada- y otras edificaciones como el colegio de La Presentación de estilo republicano tardío.

Se pueden resaltar construcciones cercanas a la Plaza de Bolívar, como el edifico del Conservatorio de Música del Tolima, la Sala de Conciertos Alberto Castilla, el conjunto arquitectónico de casas republicanas pertenecientes al Conservatorio, los seminarios Mayor y Menor, entre otros.

Es importante enunciar que el convento Santo Domingo y su insigne iglesia fueron suprimidos por el Congreso de Cúcuta de 1821 para ser convertidos en el reconocido colegio San Simón, fundado por el General Santander hacia 1822, y que su plazuela se transformó en el gran
Figura 1:

Antigua Plaza de Bolívar. Iglesia Catedral. Ibagué a principios del siglo $X X$. Fuente:

Banco de la República

Figura 2:

Actual Plaza de Bolívar. Iglesia Catedral.

Fuente:

Archivo Mario Cifuentes

1. De la Cordillera Central en donde se asientan las bases del Nevado del Tolima y los cráteres del volcán Machín, nace el río Combeima, que baña la ciudad de Ibagué. El nombre Combeima tiene una historia que viene desde la conquista española. Inicialmente los indígenas de la región lo bautizaron Cutucumay que significa oro, debido a los yacimientos auríferos de la región. El nombre actual del río deriva del cacique que vivió a sus orillas durante la época de la conquista (Ministerio de Cultura. 2011, junio). 


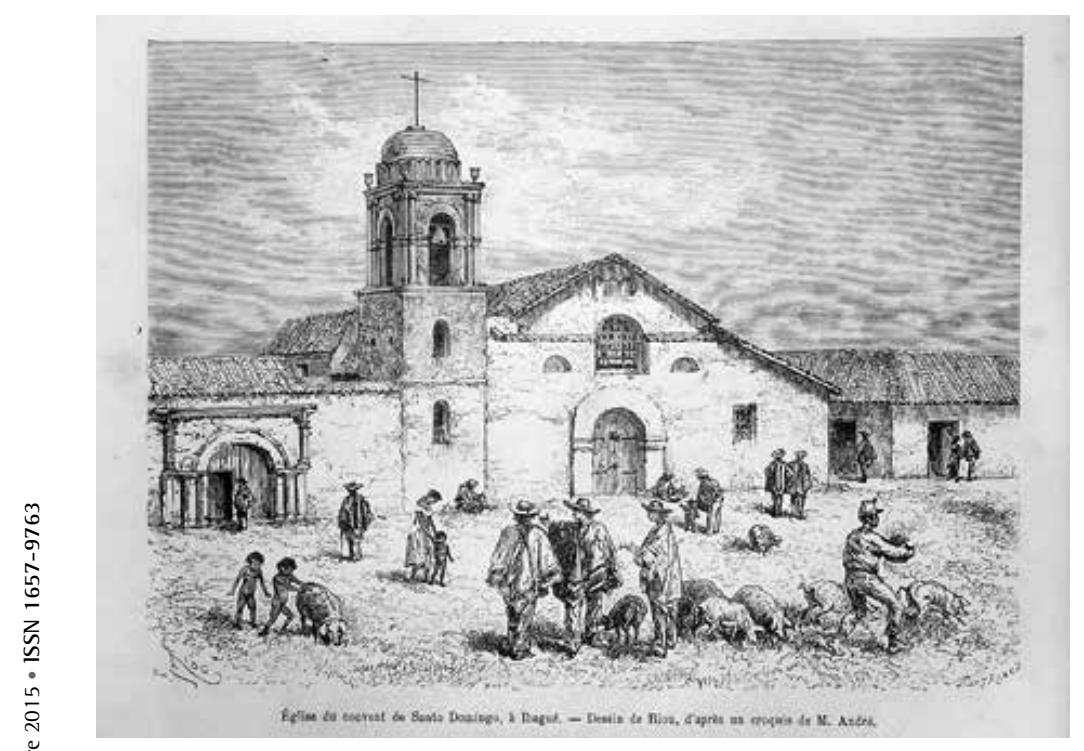

Figura 3:

Antiguo convento Santo Domingo, 1875-1876.

Fuente:

Banco de la República

Parque Manuel Murillo Toro (Figura 4) -inolvidable y recordado presidente de la República de Colombia-, rodeado por el edifico republicano de la Gobernación y la famosa casa Humboldt que aún se niega a desaparecer.

La ciudad tuvo sus inicios en los barrios La Pola, Belén y Libertador, que comprendían lo que hoy en día es el centro de la ciudad, con construcciones republicanas muy representativas y de un lenguaje claro, con características propias de la región y ornamentaciones atractivas que embellecen aún la población. A mediados del siglo pasado inicia en la ciudad un gran auge comercial, cultural y administrativo de la región permitiendo así el avance en construcciones grandiosas que ofrecen un carácter propio en su esencia de arquitectura y urbanismo.

El modernismo llega aplastante a la ciudad, bellísimas edificaciones son eliminadas para darle paso a la desmesurada modernidad que en ese tiempo aquejaba a la población. Sin conciencia, sin normas de protección y conservación, sin cuidado alguno se decide la total desaparición de emblemáticas construcciones que le daban el

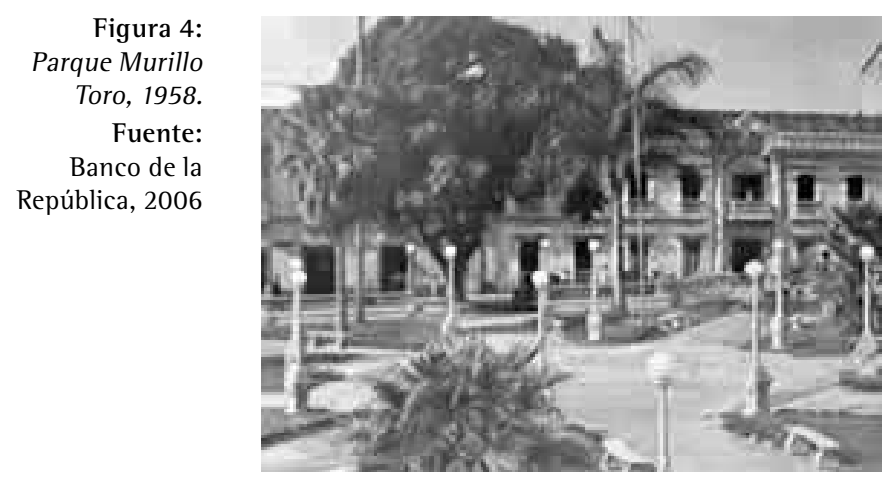

carácter de ciudad republicana por excelencia perdiendo todo su potencial. Bellísimas estructuras como el edificio de la Gobernación, el colegio San Simón, el Parque Murillo, hasta la muy nostálgica Estación del Ferrocarril sufrieron importantes estragos, así como antiguos bancos, teatros, casas, etc., que finalmente, a partir de fotografías, entran en la recordación de algunos y en la memoria de otros.

El modernismo, a pesar de su fructífero atentado contra la memoria arquitectónica, permitió que algunos estilos de los años cuarenta y cincuenta llegasen a configurar otro lenguaje propio de la ciudad. El Art Déco llega a su máxima expresión en construcciones que aún se conservan y generan en el transeúnte una imagen propia del lugar, entre ellos el edifico de correos -hoy sede de la Dian-, el bellísimo Teatro Tolima, la Alcaldía Municipal y algunas casas de tipo residencial que se ubican en los barrios tradicionales de la ciudad entrelazados con la arquitectura republicana de algunas edificaciones, como construcciones típicas que se niegan a morir; sin olvidar la arquitectura rural que en tiempos de la colonización antioqueña se ven muy bien representadas, como es la casa del inmortal escritor Jorge lsaacs, hoy en ruinas.

lbagué, reconocida por sus eventos culturales y artísticos a nivel nacional, ha recibido distintos nombres: Ciudad Cuartel, así la llamaron los españoles por ser fundada más como puesto militar; Ciudad Asalto, porque hacia 1606 los Pijaos asaltaron la población; Ciudad Nostalgia, por Policarpo Varón, célebre escritor tolimense; lbagué, pueblo con maquillaje de ciudad, por Gregorio Rudas gobernador del Tolima 19801982; Ciudad de Forasteros, lo dijo un inmigrante en los años veinte; la Ciudad del Arroz, la llamó Fidel Castro; hasta finalmente reconocerse como Ciudad Musical, por la cultura musical que aún vive desde eventos folclóricos hasta modernos y vanguardistas; toda esta producción cultural es lo que realmente hace que lbagué sea reconocida y valorada desde todos sus aspectos.

Se puede decir que toda esta influencia cultural, constructiva, arquitectónica y urbanística es una representación única de la ciudad (Figura 5) que hace de ella un precioso compendio histórico de disímiles hechos y que guarda en sus entrañas todo un mundo de conceptos eclécticos en sus construcciones haciendo en ella un lugar 
exclusivo para conocer, digno de ser defendido y conservado.

\section{Retrospectiva histórica y constructiva del Panóptico de lbagué}

En las afueras de la ciudad, en su costado norte, se ubica el enigmático edificio del Panóptico de lbagué, imponente y robusta construcción de 1862 del arquitecto William Blackburn (Figura 6). La maratónica labor constructiva bajo la administración y gobierno de Manuel Casabianca, regente por esos tiempos, denota una impresionante responsabilidad con la edificación destinada a los presos.

Es importante recordar que Jeremy Bentham, pensador, ideólogo y botánico inglés, llamado padre del Utilitarismo, hacia 1800 genera una reforma penitenciaria a partir de la tipología constructiva en cruz griega. Esta configuración permite que los pabellones mantengan la misma proporción y distancia, lo que facilita vigilar todo desde un punto central; característica por la cual toma el nombre de Panóptico, que proviene del latín Pan: todo, Opticus: visión. Esta idea se hizo efectiva no solo para cárceles sino para fábricas y escuelas.

Bajo esos criterios, el General Casabianca ordena erigir una monumental obra para albergar personas perseguidas por la ley y dar seguridad a la ciudadanía; “[...] en Febrero de 1891 se inician los trabajos para la construcción del Panóptico de lbagué, claro ejemplo de la Arquitectura Republicana, hoy declarada Monumento Nacional” (Tolima Siete Días, 2002, octubre, p. 44). Se planeaba construir la cárcel en la población de Mariquita, a escasas horas de lbagué hacia el norte, pero según la ordenanza del 18 de julio de 1888 la Asamblea Departamental decide hacer la construcción en lbagué y Neiva, otra población cercana hacia el sur de la región; “[...] la Asamblea Departamental, establece centros de castigos en la ciudad de lbagué y Neiva para los condenados a las penas de presidio, reclusión y prisión, conforme a lo dispuesto en el Código Penal [...]" (Cuartas, 1994, noviembre, p. 110). En 1889 se ordena finalmente la ejecución de la obra bajo la dirección del ingeniero Mirtiliano Sicard Pérez.

Este edificio se convierte en una de las más cabales representaciones de la arquitectura carcelaria del país en el siglo XIX. Se erige sobre un globo de terreno perteneciente a la hacienda

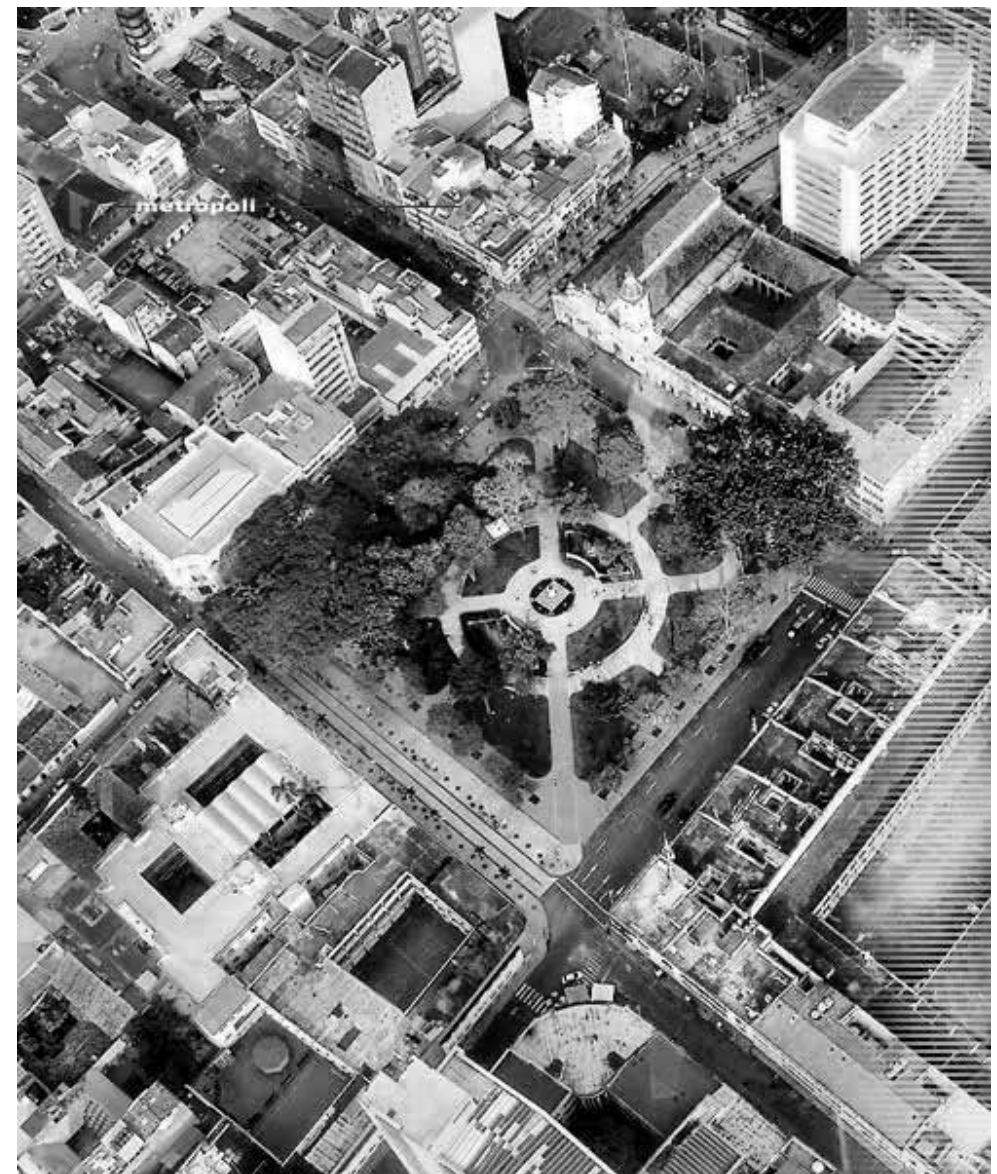

Belén cuyo propietario era Don Claudio Rengifo quien la vendió para tal fin al departamento (Fondo Mixto de Cultura del Tolima, 1997, octubre). Una vez concebida, la edificación comienza a ser reconocida en el país no solo por su monumentalidad arquitectónica y constructiva sino por su uso y funcionalidad.

Hacia 1914 ya contaba con 200 reclusos, para cada interno se destinaban una celda de $2 \mathrm{~m}$ por $3 \mathrm{~m}$ por $4 \mathrm{~m}$, conformada con una estructura muraria en cal y canto con muros de $60 \mathrm{~cm}, 50 \mathrm{~cm}$ y $40 \mathrm{~cm}$ de grosor. Esta edificación de dos niveles

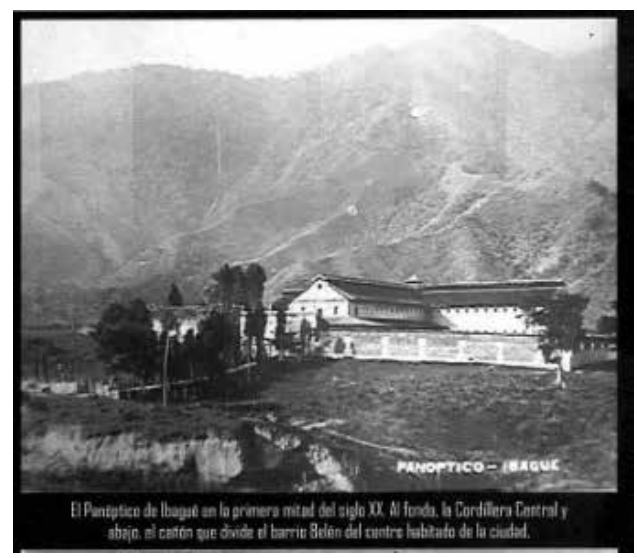

Figura 5:

Actual centro histórico de Ibagué. Vista aérea.

Fuente:

Google

Figura 6:

Antiguo Panóptico.

Fuente:

Sociedad Colombiana de Arquitectos, 2007, octubre 
la configuran cuatro pabellones dispuestos con corredores en madera y un cimborrio que se eleva en su punto central para servir de iluminación y ventilación. La estructura original del Panóptico consta de una construcción cruciforme caracterizada por cuatro corredores de $70 \mathrm{~m}$ de largo y seis de ancho, en cada corredor se abren 13 celdas por ambos lados.

La compleja cubierta de estructura de madera a manera de cerchas rey, está conformada por piezas en abarco de río configurando su tramado perfecto con ensamblajes en rayo de Júpiter, caja y espigo y media madera, complementados con un tramado de varas de caña brava sobre el cual, finalmente, reposan las tejas de barro. Sobre la cubierta principal se eleva una segunda más pequeña siguiendo la linealidad de la principal en forma de lucarna para permitir su ventilación e iluminación sobre cada pabellón.

Por el aumento de presos se ve la necesidad de subdividir los pabellones y de construir obras anexas, además, la cubierta sufre algunos daños producidos por el peso de tortas de concreto de $8 \mathrm{~cm}$ de grosor que se instalaron por seguridad y evitar la fuga de presos, las cuales ocasionaron flectaciones y pandeos en sus tirantes principales y aplastaron la caña brava, lo que, por fortuna, no comprometió la totalidad
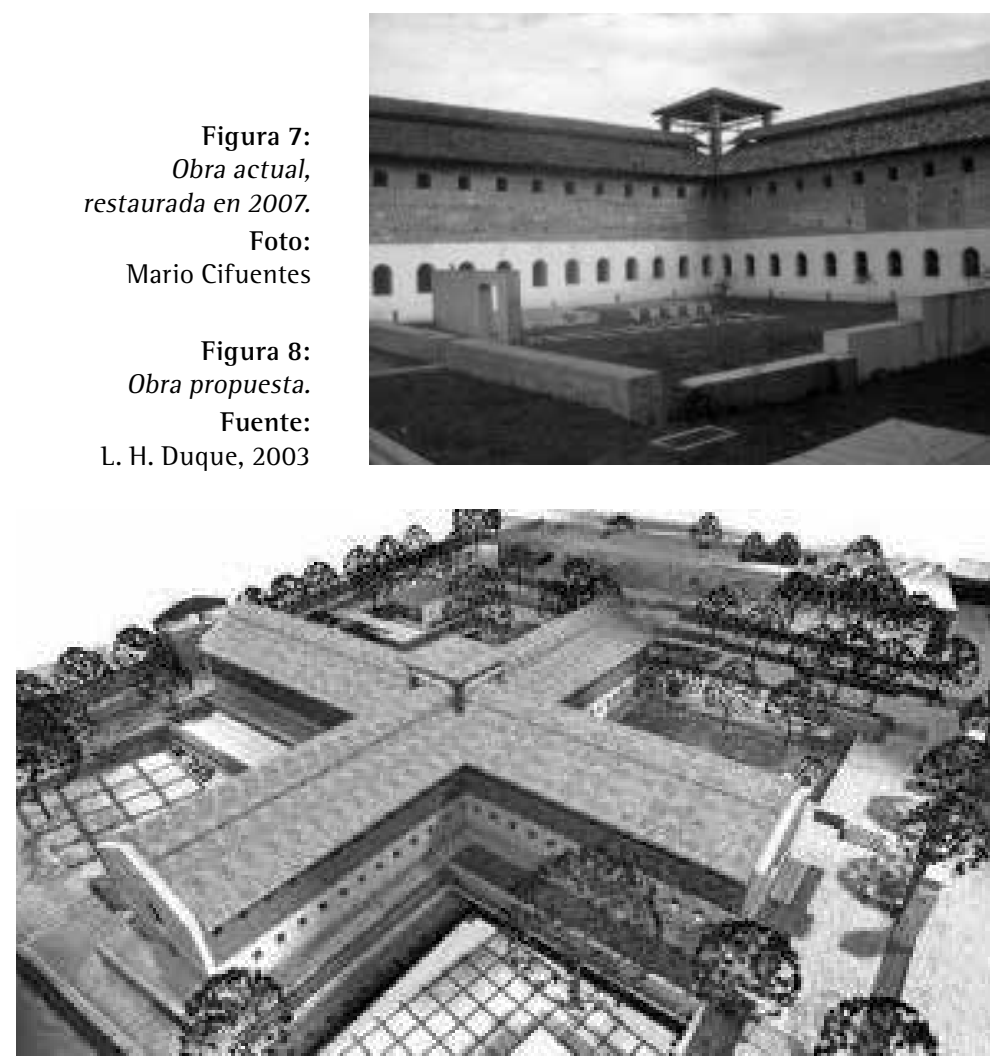

de la estructura original; “[...] por el aumento de la población en la cárcel en diversas épocas se fueron haciendo varias modificaciones y [...] también nuevos volúmenes que no alteraron para nada la estructura original" (Sociedad Colombiana de Arquitectos, 2007, octubre, p. 10). El gran número de obras anexas generaron nuevos espacios destinados para cárcel de mujeres y hombres, aulas de estudio, casinos, locales, almacén de artesanías, lo que creó hacinamiento en sus celdas, depresión y caos. A partir de estas transformaciones el nombre de Panóptico se cambia por el de Penitenciaría Nacional de lbagué.

El edificio fue declarado Monumento $\mathrm{Na}$ cional en 1987 en virtud de lo cual deberá ser destinado a fines culturales; "Ante gestiones realizadas por el Instituto Tolimense de Cultura en el año de 1987, fue inscrito como parte del patrimonio histórico y artístico de la Nación, el edificio original del Panóptico, por formar parte de la memoria colectiva de los ibaguereños y por constituirse en un símbolo de la arquitectura del siglo XIX, de acuerdo con lo dispuesto en la Resolución 010 del 3 de Diciembre de 1987, suscrita por el Presidente del Concejo de Monumentos Nacionales" (Cuartas, 1994, noviembre, p. 117);

Se decide su cierre definitivo en 2003 y se presenta una propuesta para restaurar el Panóptico como museo de la ciudad (Figura 7). A través de un concurso nacional, cuyo participante ganador fue el arquitecto Luis Humberto Duque Gómez, se constituye un proyecto de restauración del edificio patrimonial destinado como espacio museístico y un parque urbano con nuevos volúmenes para actividades comerciales, artesanales y culturales (Figura 8)

La idea principal del proyecto de restauración no es suprimir la historia de un edifico destinado para cárcel sino, por el contrario, recuperar las celdas originales, niveles, estructuras murarias y cubiertas, incluida la policromía que los detenidos habían plasmado allí con el fin de permitir recorrer sus espacios para reconocerlo y crear conciencia patrimonial (Figura 9). Cabe resaltar que el proyecto se destinó para ser la sede principal del Centro de los Derechos Humanos dado que lbagué fue declarada Capital Andina de los Derechos Humanos. La creación de un nuevo paisaje urbano con el monumento permite respetar los signos de la historia, la 
memoria cultural y social de lbagué y logra una reflexión sobre los valores culturales, civiles y sociales de su población y región.

\section{Proceso constructivo y de restauración del Panóptico}

Respecto al proceso de restauración del inmueble del Panóptico y la casa del alcaide -volumen más pequeño anexo al monumento que cumple como memoria arquitectónica como conjunto carcelario-, se procede a su intervención y planteamiento de metodología de la obra, que parte del resumen de su historia llega hasta el estado actual de la construcción (Figura 10). Esta breve descripción nos indica que ambas edificaciones ameritan un proceso de intervención adecuada, metodológica y pertinente para conservar su lenguaje original arquitectónico y constructivo; sugiere, además, dar continuidad a la obra de restauración hasta el final, ya que su comportamiento obliga a un cuidadoso proceso de intervención y un estudio preciso en las características arquitectónicas y de sus sistemas constructivos para lograr el objetivo de conservar y mantener el conjunto arquitectónico como hecho patrimonialy, a la vez, permitir su estabilidad, seguridad, funcionalidad y durabilidad destinado al nuevo uso propuesto (Figura 11).

Una vez en se hace su reconocimiento como inmueble patrimonial y se ve la necesidad de hacer un proceso de recuperación y preservación, se procede a hacer los estudios preliminares con el fin de conocer el comportamiento y estado de las dos edificaciones (Panóptico y casa del alcaide).

Posteriormente se da cumplimiento a los procesos establecidos para la intervención. Según la metodología planteada se procede a desarrollar las actividades preliminares de liberación de volúmenes nuevos y anexos (Figuras 13 y 14) que no cumplían con el lenguaje original, además de conservar uno de los pabellones como testimonio fiel de experiencias vividas en su interior (Figura 12), así como la instalación de una sobrecubierta para protección de las edificaciones originales (Figura 15), el desmonte de piezas de maderas en su estructura de cubierta para ser recuperadas, restituciones de muros a su estado original, entre otras actividades.

Por lo anterior, a continuación se mostrarán por cada item constructivo (subestructura,

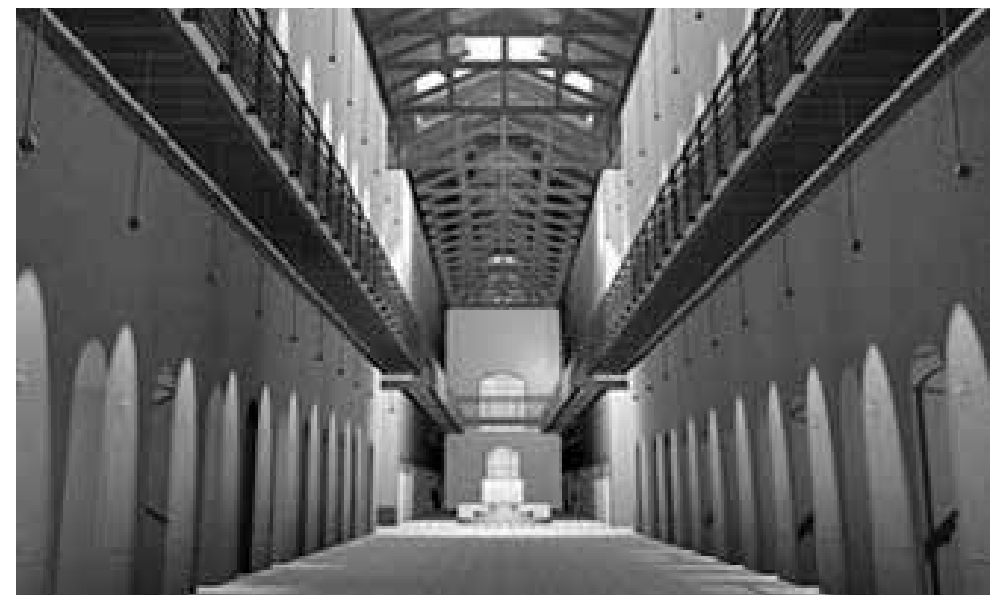

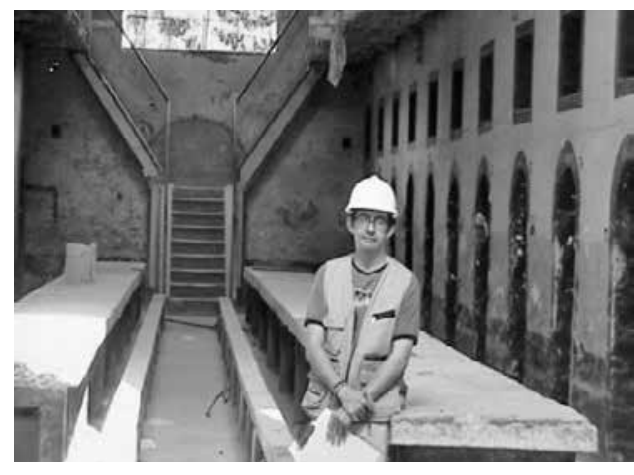
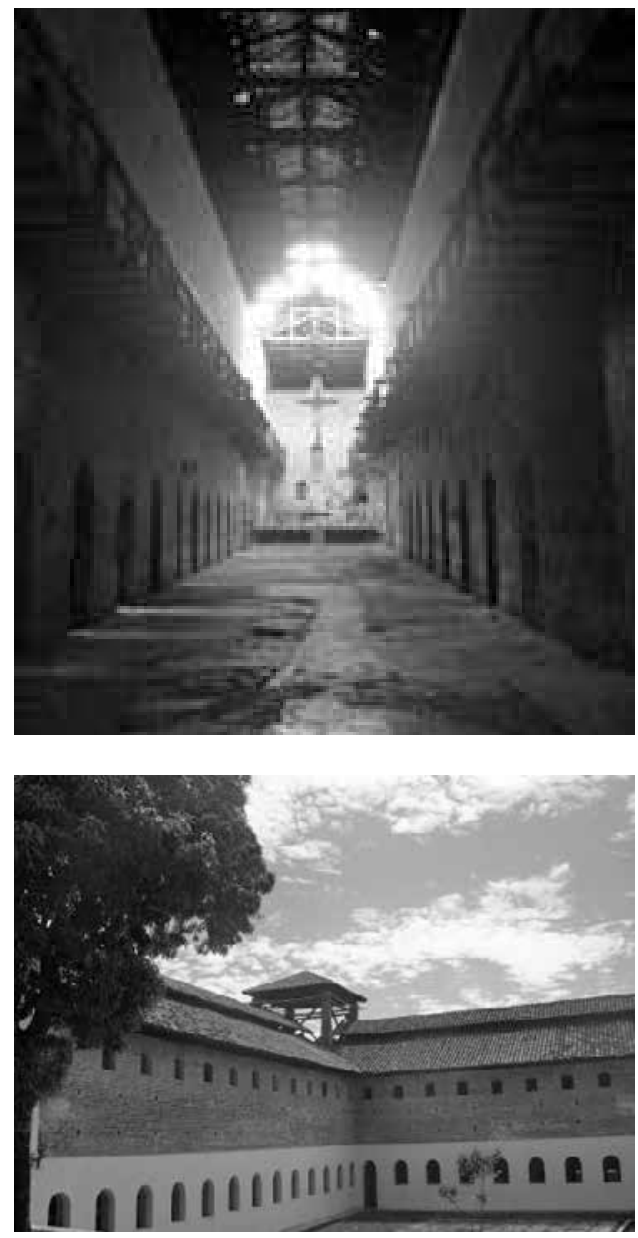

Figura 9:

Propuesta interior.

Fuente:

Arq. L. H. Duque

Figura 12:

Pabellón testimonial durante el proceso de intervención.

Fuente:

Mario Cifuentes

Figura 10:

Estado del edificio antes de su restauración.

Fuente:

Mario Cifuentes

Edificio durante el proceso de restauración. Fuente: Mario Cifuentes 
Figura 13:

Liberación de

construcciones anexas.

Fuente:

Mario Cifuentes

Liberación de volúmenes no originales, ala este.

Fuente:

Mario Cifuentes
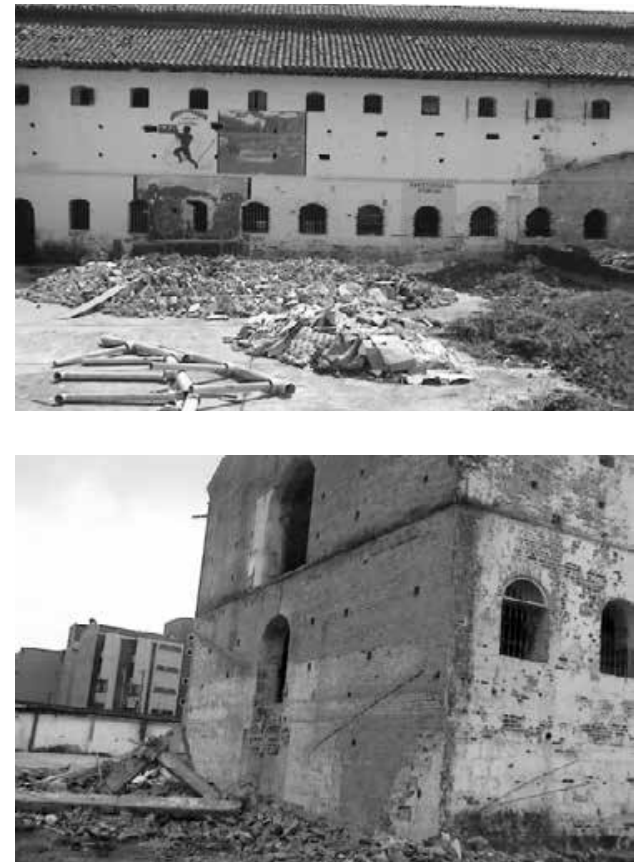

Figura 15: Instalación de la estructura de la sobrecubierta, ala norte.

Fuente:

Mario Cifuentes

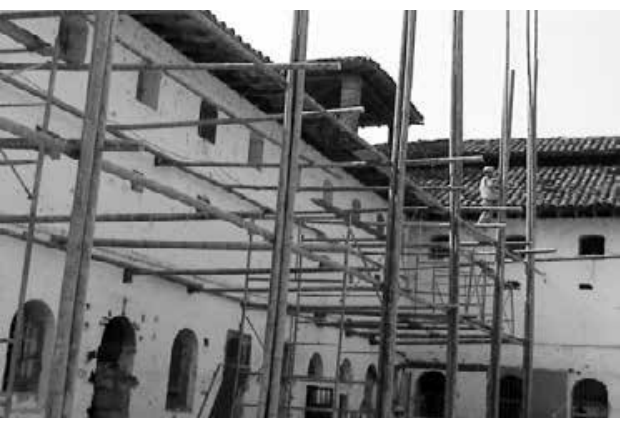

Figura 16: Proceso restitución

de muros.

Fuente:

Mario Cifuentes

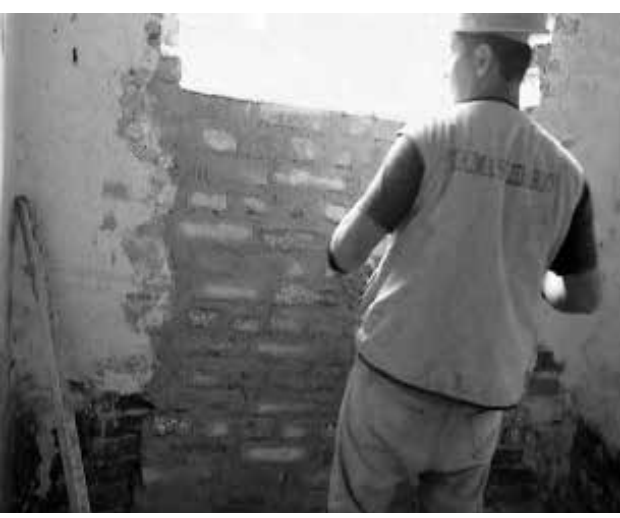

Figura 17:

Vista de la restitución

de fachada.

Fuente:

Mario Cifuentes

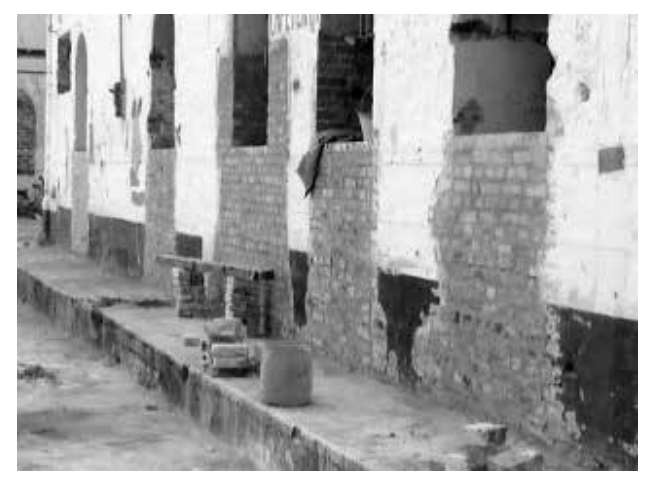

estructura, sobreestructura y acabados), los procesos de intervención logrados y las recomendaciones para llegar a feliz término con la obra. Se destaca que todo inmueble sometido a este tipo de intervenciones debe llevar estrictos procesos metodológicos en su ejecución.

\section{a. Subestructura}

En cuanto a la cimentación, el inmueble se asienta sobre una cama de cimientos y sobrecimientos en piedra zonga y media zonga respectivamente, que en los patios 3 y 4 sobresalen del suelo con un interesante manejo de aparejo de sus piezas que solucionan la inclinación del terreno. Durante la ejecución se realizaron actividades de liberación, recuperación y protección de las piezas del sobrecimiento que quedan a la vista en las alas este y norte donde es importante tener en cuenta que aún falta el trabajo de recalces con el fin de mejorar su aspecto como principio en la subestructura.

En lo relacionado con los pisos, el tablón de gres utilizado originalmente en el edificio Panóptico fue recuperado e instalado después de una cuidadosa liberación consistente en desmontar los pisos que no eran pertinentes según la época en que fueron colocados. Luego se procede a instalar el tipo de pisos contemplado en el proyecto, que da homogeneidad a toda la edificación.

Para mantener la memoria de técnicas y acabados en los pisos de las celdas, se realizaron superficies en cemento afinado con las que se logra cierta rusticidad en los ambientes dado que en tiempos anteriores el piso era a base de tierra $\mathrm{y}$ sin ningún tratamiento.

Finalmente se plantea una cámara de ventilación alrededor del edificio para evitar daños provocados por la humedad y conservar por mucho la estructura muraria que en ella se asienta.

\section{b. Estructura}

Respecto a la estructura muraria, tanto al interior como al exterior se ha hecho todo el proceso de restitución de muros, liberaciones y recuperaciones de vanos de ventanería y puertas (Figuras 16 y 17), y se conservaron algunas pinturas murales y escritos de gran trascendencia. Es de suma importancia resaltar la recuperación del ladrillo en el momento de su desmonte como uno de los logros de la obra; esta labor consistió en que durante la cuidadosa liberación hecha en los muros que separaban las alas y pabellones, se 
observó que el sobrante de dichos muros contenían gran cantidad de ladrillos en muy buen estado lo que obligó a un estudio de calidad de esas piezas, el resultado fue que pudieron reutilizarse y fueron aprovechadas en la restitución de los muros que ameritaban recuperarse, así se mejoró la calidad y homogeneidad en todo el conjunto murario, se avanzó en tiempo y se ahorró en costos (Figura 18).

Cabe resaltar que todo edificio de bien patrimonial por norma debe llevar su reforzamiento estructural para cumplir con la estabilidad, seguridad y funcionalidad de la edificación, por lo cual, una vez se reanuden las actividades esta debe tomarse como ítem prioritario. Los reforzamientos metálicos planteados por la firma PYG se ubicarían en las puntas de cada ala o pabellón del edificio y cada tres celdas. Esta intervención aún no se ha cumplido.

Por otra parte, los murales denominados como "pintura carcelaria" son cuidadosamente recuperados y luego se les encierra en un recuadro para protegerlos mientras se hace la intervención, esto con el fin de conservar la lectura muralística interior y conocer las necesidades de los internos plasmadas en sus muros, al igual que en las jambas de ventanas y puertas, ya que presentan un gran manejo de colorido y contraste (Figura 19).

Existe la clara decisión de conservar un ala como único testimonio latente del estilo de vida que alli se experimentaba, por ello se resuelve conservar la mayor cantidad de detalles tanto en celdas como en los comedores ubicados en el pasillo de ese pabellón, así como también en la escalera testimonial ya que ella guarda recuerdos de la vida carcelaria que se convierte en memoria palpable de la situación de degradación a los derechos humanos (Figura 20).

En el ala de conservación es importante hacer una intervención cautelosa mediante la recuperación de cada uno de los elementos que compone el espacio testimonial: restitución de comedores; recuperación de los tallados de juegos de mesa y azar en sus superficies, que muestran los momentos lúdicos y la necesidad de diversión que tenían los internos; restitución de algunas áreas en los pisos que fueron intervenidos por los mismos internos para el manejo de sus puertas de rejas; conservación de todas las pinturas y escritos carcelarios, colores originales plasmados por los presos ya que con ellas se intentaba lograr un aspecto agradable en sus recintos; $y$ el manejo de

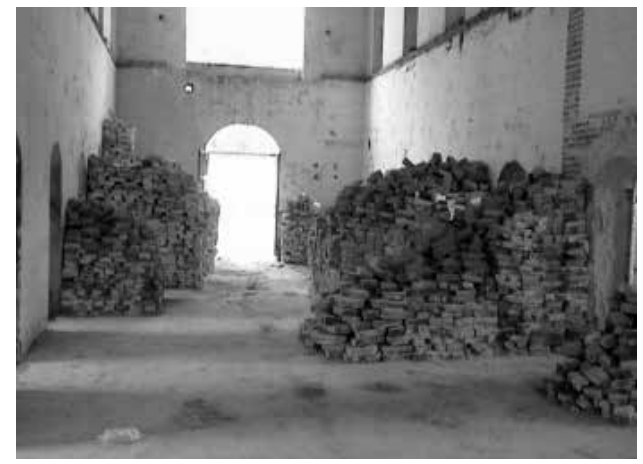

Figura 18:

Liberación de muros no originales.

Fuente:

Mario Cifuentes

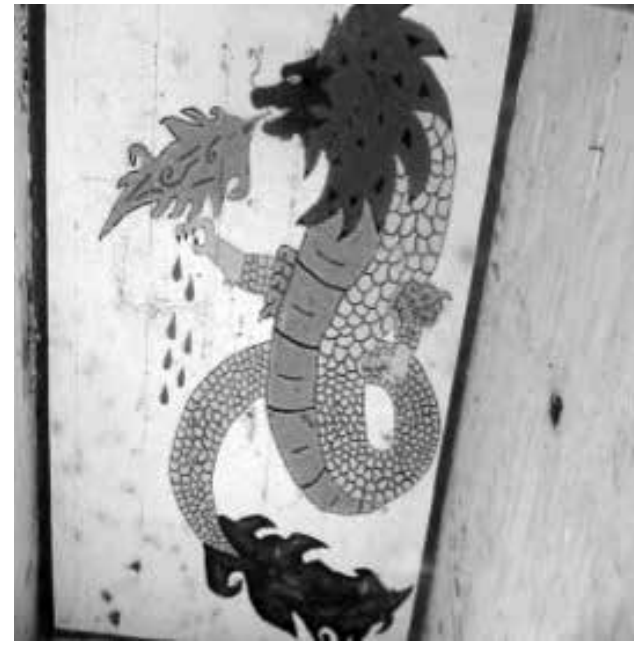

Figura 19:

Detalle pintura carcelaria.

Fuente:

Mario Cifuentes

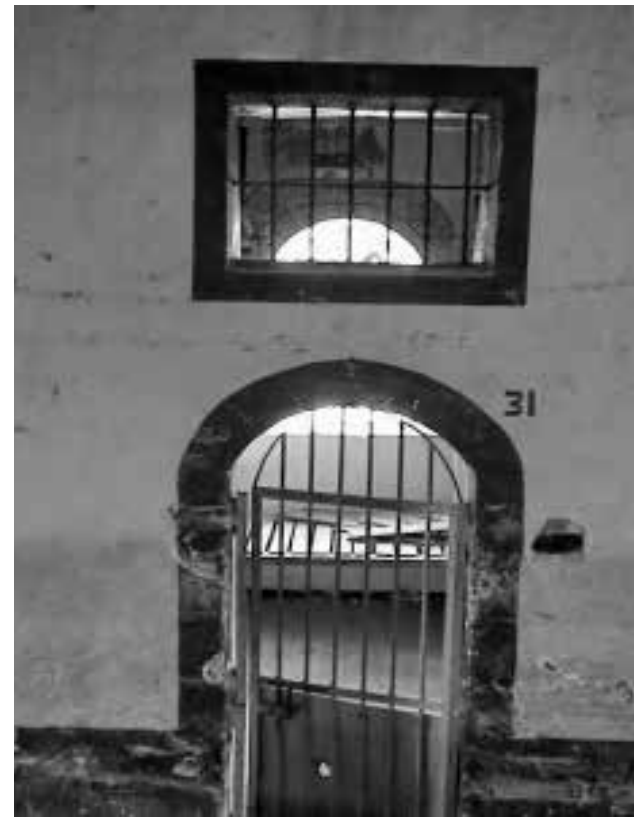

Figura 20:

Detalle de celda testimonio.

Fuente:

Mario Cifuentes limpieza y reubicación de las piezas de maderas donde se encontraban los camarotes y mezanines en cada celda, sin embargo, algunas contienen pedazos de periódicos adheridos a sus maderas, lo que se recomienda no retirarlos sino reubicarlos y volverlos a pegarlos, su significado era sentido de protección para el frío y en algunos casos la 
Figura 21:

Detalle de restitución

muraria.

Fuente:

Mario Cifuentes

Figura 22:

Detalle de restitución parcial de muro.

Fuente:

Mario Cifuentes
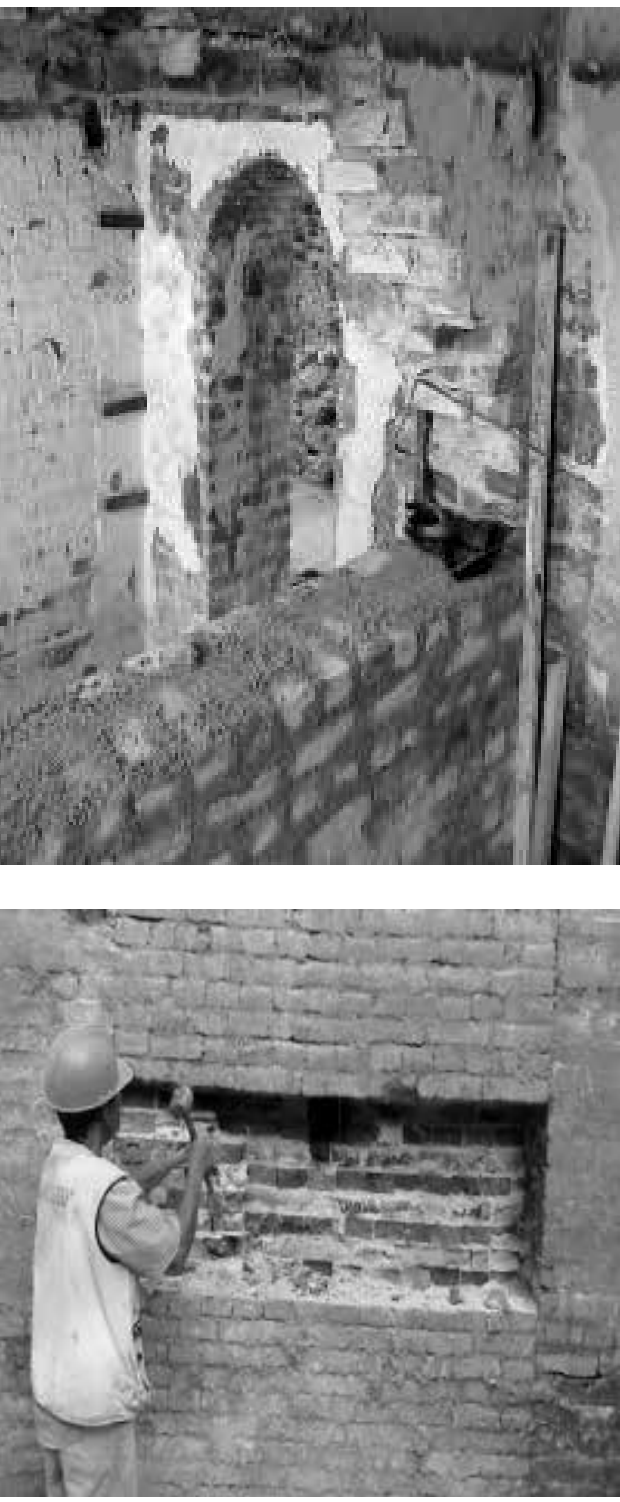

Figura 23:

Puerta original acceso.

Fuente:

Mario Cifuentes

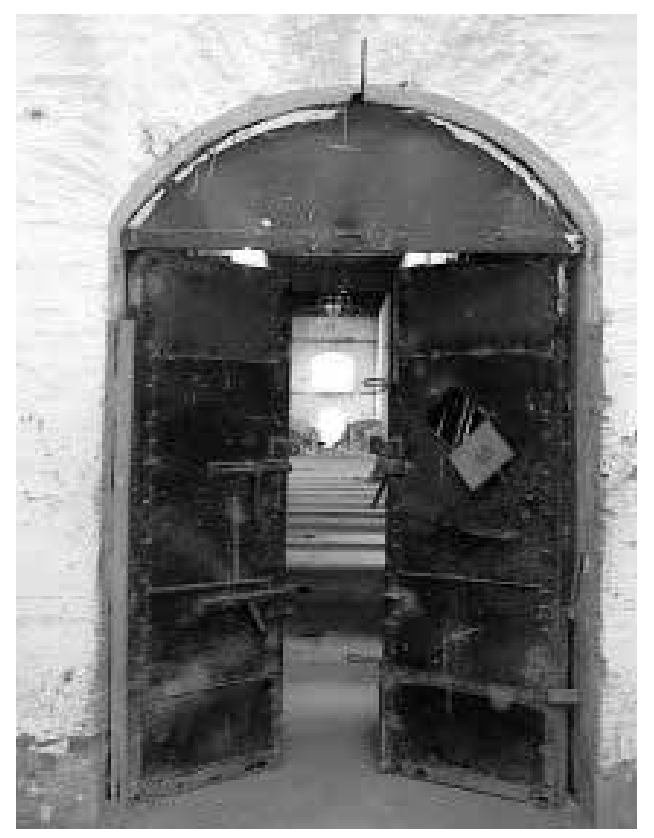

necesidad de sentirse acompañados y actualizados en noticias sobre hechos cotidianos.

Las puertas de madera y metálicas se deben conservar, lo que significa entender los cambios que sufrió la antigua cárcel y observar los distintos tipos de materiales manejados en cada periodo.

Las celdas de los otros pabellones del edificio se conciben como sitios de exposiciones, salas de lectura e investigación, y en su segundo nivel se destinan para espacios de oficinas, archivos y documentos, lo que se configura con un tramado de corredores en madera de sapán, rematados con antepechos metálicos y comunicados por puentes en metal que trabajan como agentes de reforzamiento para consolidar la estructura interna de sus corredores y que conjugan muy bien con la carpintería de madera en su interior.

En los accesos de algunas celdas conformados por arcos de medio punto se decide dejar testigos o huellas de mampostería para exponer el complejo manejo de sus piezas en aparejos solucionados para muros de $60 \mathrm{~cm}, 50 \mathrm{~cm}$ y $40 \mathrm{~cm}$.

Una de las anécdotas más sorprendentes de este trabajo fue el descubrimiento de una puerta emparedada al lado de la puerta principal de acceso al edificio (Figura 23), con características carcelarias de los años veinte y que hace un interesante juego con la original, ambas son en hierro forjado pero con mecanismos particulares de seguridad y control que hacen del espacio uno de los atractivos del monumento.

Finalmente, respecto a los vanos tanto interiores como exteriores, muchos de ellos fueron modificados para control y seguridad de los presos distorsionando completamente el lenguaje original de las ventanas, por tanto, se debió proceder a liberar algunas que fueron totalmente tapiadas, devolverles la originalidad de su dimensión restituyendo parte de ellas, recuperar muchas mutiladas y otras que conservaban la misma proporción para lograr así el manejo homogéneo de las aberturas en todo el edificio (Figuras 21y 22).

\section{c. Sobreestructura}

La parte correspondiente a la cubierta en cercha rey compleja, hecha en abarco de río (Figura 24), es la que presenta mayor problema en su estructura; durante su ejecución se procedió a hacer todo el desmonte de piezas desde las tejas hasta el cambio de maderas que 
se encontraban en mal estado (Figura 25), sin olvidar que en las alas este y norte del edificio estas poseían sobre sus estructuras, como ya se mencionó, una torta de concreto de $8 \mathrm{~cm}$, observándose en algunas piezas aplastamientos, pérdidas en su capacidad de soporte, pandeos y flectaciones y que requería hacer un cuidadoso proceso de liberación y recuperación. Para estas piezas nuevas junto con las originales que tenían buen aspecto se procedió a la respectiva inmunización e instalación, además de un reforzamientos en el material metálico para su estabilidad y seguridad. Luego se continuó con el montaje de la caña brava como material original de toda la estructura, sin olvidar que se debía remplazar la anterior pues se encontraba totalmente aplastada y afectada en toda el área de la cubierta. Así se procedió a su respectiva instalación ya que esta sirve de soporte para la ubicación de la teja de barro, de la cual se recuperó en un 50\% de la cubierta total.

Es importante destacar el logro con la instalación del reforzamiento metálico del crucero, donde antes se observaba cierta inestabilidad a partir de los pilares encontrados en el cimborrio, así se logró la seguridad del mismo y se configuró mejor su compleja estructura de madera en la cubierta (Figura 26).

Respecto a los daños en la estructura, es importante controlar la intrusión de animales mediante la instalación de anjeos y mallas, además, aplicar inmunizaciones contra xilófagos y proteger cada una de sus piezas al verificar su seguridad y conservación.

\section{d. Acabados}

Se conoce que el item de acabados es el más importante y en una restauración es prioritario ya que indica la calidad estética y presentación del inmueble en su fecha de entrega, más cuando la construcción es de orden patrimonial porque guarda toda una trascendencia histórica y constructiva que, posteriormente, va a ser apropiada por la comunidad (Figuras 27, 28 y 29). Es de suma urgencia que en la etapa de acabados se haga un trabajo cuidadoso en los detalles anteriormente mencionados, principalmente en el crucero, donde se espera que el montaje del reforzamiento estructural sea complementado con la instalación de la ventanería y el cierre en el cimborrio del crucero.

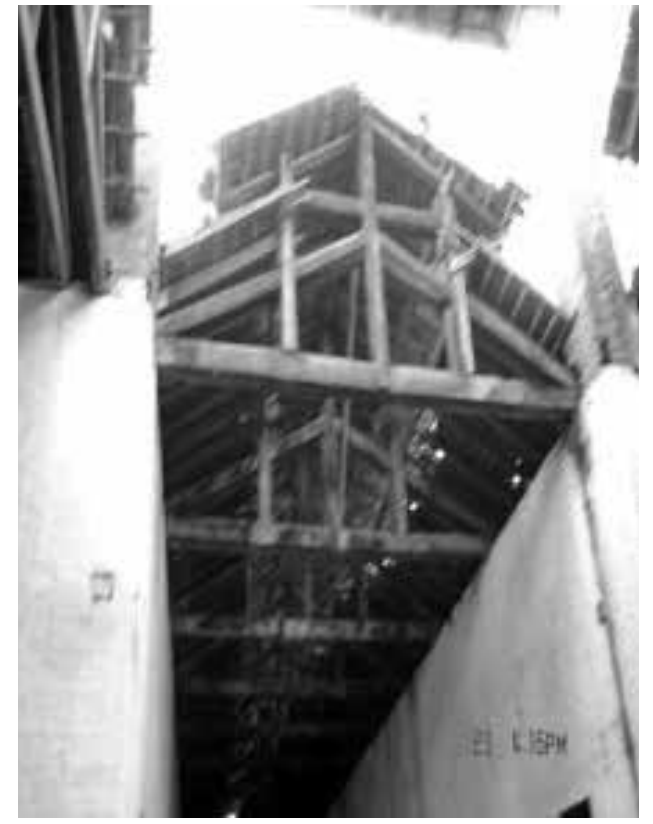

Figura 24:

Estructura de cubierta

Cercha Rey.

Fuente:

Mario Cifuentes

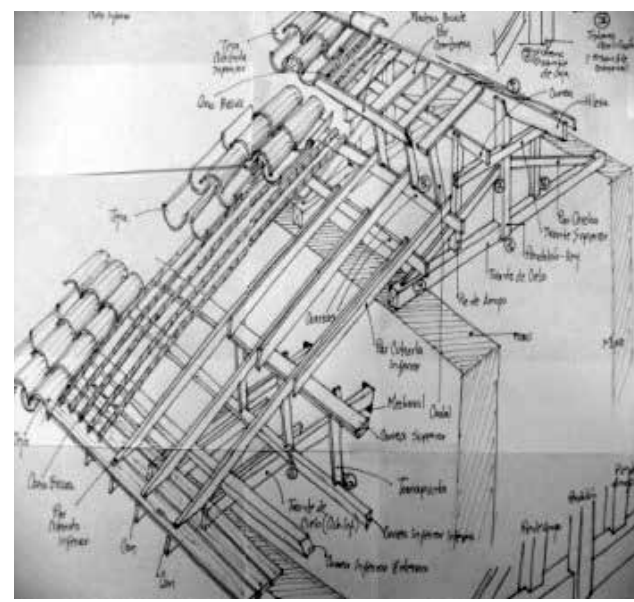

Figura 25:

Levantamiento de piezas cubierta.

Fuente:

Dibujo Mario Cifuentes

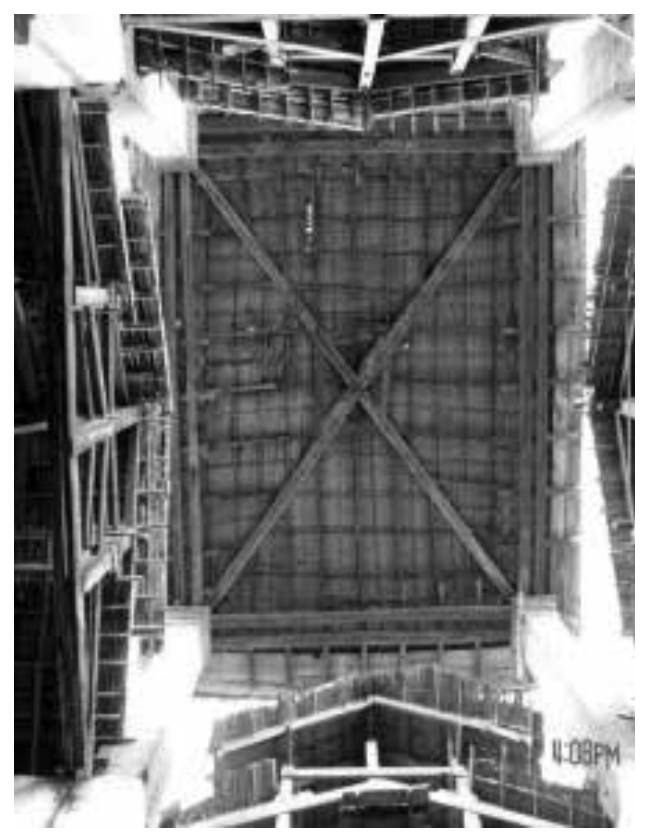

Figura 26:

Estructura de cimborrio.

Fuente:

Mario Cifuentes. 
Figura 27:

Propuesta interior

del edificio.

Fuente:

Diseño de L. H. Duque

Figura 29:

Propuesta de diseño exterior.

Fuente:

Diseño de L. H. Duque

Propuesta para el ala testimonial.

Fuente:

Diseño de L. H. Duque
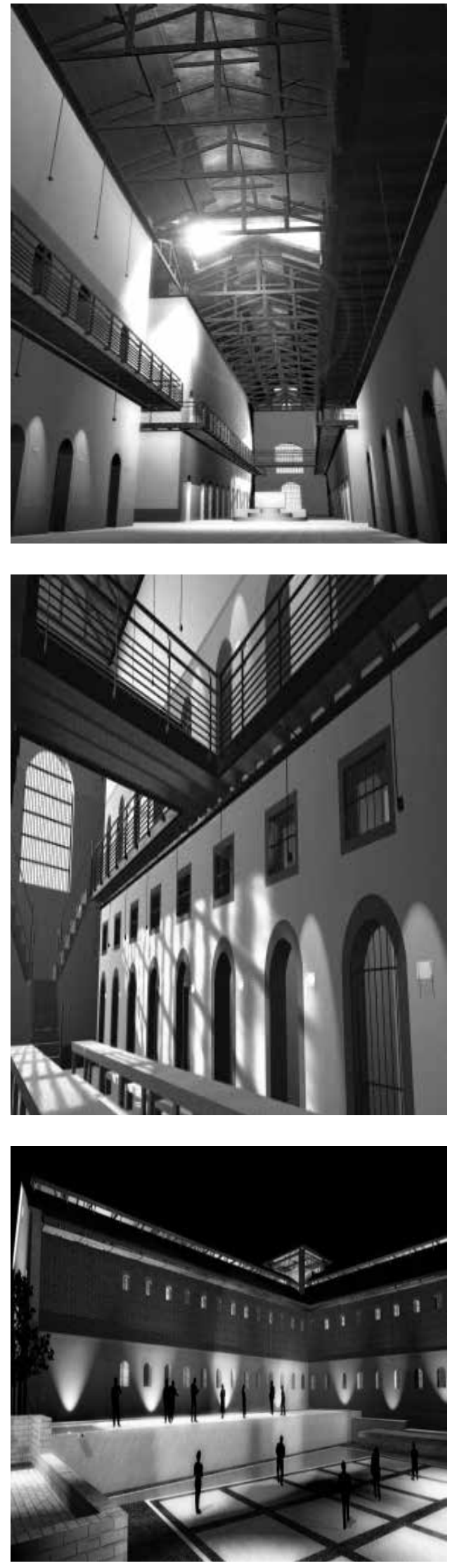

La óptima y pertinente intervención de una edificación de gran envergadura como es el edifico Panóptico, sin olvidar la casa del alcaide y el portal de acceso, hacen de esta obra una de las más insignes representaciones de arquitectura carcelaria a nivel mundial. El excelente manejo de sus materiales, la cuidadosa metodología de su proceso, la entrega impecable del proyecto hacen de él una estructura digna de exponer y presentar a todas las generaciones venideras, y así crear conciencia y reforzar sus vínculos más arraigados con la cultura, el arte y los valores sociales (Figura 30).

\section{Conclusiones}

La idea de conservar el Panóptico de lbagué no solo como edificio patrimonial y monumento nacional, sino como sede principal de los Derechos Humanos en la ciudad de lbagué, Capital Andina de los Derechos Humanos, hacen de este proyecto uno de los más destacados del país y entre los edificios con particularidades semejantes en el continente, entre ellos el de Quito, hoy facultad de Bellas Artes y Escuela de Teatro, el de Ciudad de México, que alberga el Archivo General de la Nación y el de Bogotá, sede del Museo Nacional.

La preocupación ahora es la falta de recursos económicos para continuar con la obra y dar fin a la restauración de los inmuebles pues, tristemente, la obra fue suspendida. Los daños están aumentando y las edificaciones, tanto el Panóptico como la casa del alcaide, están en espera de ser recuperadas urgentemente. Exponer este trabajo, más que una muestra de su proceso es un grito de auxilio para salvar nuestro patrimonio.

Un proceso de intervención metodológica y detallada garantiza la durabilidad, seguridad, estabilidad y funcionalidad del inmueble, pero si en algún momento este proceso se obstaculiza y se frena, los daños pueden aumentar, afectar más rápidamente lo saneado, lo nuevo se perdería y podría llegar a ser irreversible su recuperación.

El Panóptico de lbagué merece todo el reconocimiento como inmueble patrimonial. No se busca que sea un inmueble embalsamado sino que mediante la recuperación arquitectónica, constructiva, urbanística e histórica se generen otras características de tipo funcional para el provecho de las nuevas generaciones en los ámbitos nacional e internacional. 
Ciudad y monumento, lbagué y Panóptico, son las razones por las que el visitante debe conocer la región y el lugar y, al igual que la ciudadanía, valorar todo el contenido histórico, arquitectónico, constructivo y urbanístico que poseen resaltando las cualidades culturales, artísticas, cívicas y sociales de nuestra tierra.

\section{Referencias}

Banco de la República (2006). Tolima Publicación digital Banco de la República. Bogotá: Biblioteca Luis Ángel Arango. Recuperado de http://www.banrepcultural.org/museodel-oro/sociedades/tolima

Cuartas, A. (1994). Ibagué ciudad histórica, 101. lbagué: Gobernación del Tolima - Pijao Editores.

Fondo Mixto de Cultura del Tolima (1997, octubre). lbagué y sus múltiples rostros. Enciclo-

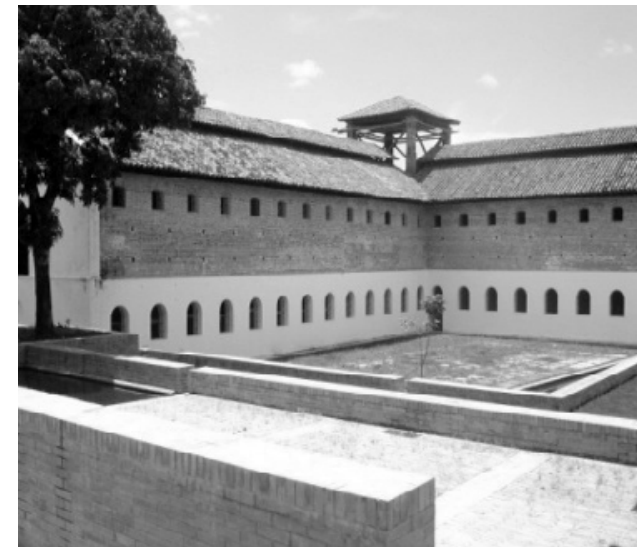

Figura 30: Vista del estado actual del edifico restaurado. Fotografía: Mario Cifuentes pedia del Tolima. (Tomo Il, vol. 122, p. 133). lbagué: Pijao Editores.

Ministerio de Cultura (2011, junio). Sistema Nacional de Información Cultural. Tolima.

Sociedad Colombiana de Arquitectos (2007, octubre). 111 semana de la Arquitectura, lbagué. Urbánita, 2, 10.

Tolima Siete Días (2002, octubre). Así es lbagué. Tolima Siete Días, semanario de El Tiempo, p. 44. 